\title{
Accountability Complexities in Non-governmental Organisation: A Reflection of Practical Mechanisms for Instilling Accountability in Selected Tanzania's Non-governmental Organisations
}

\author{
Richard Sikira \\ Institute of Accountancy Arusha
}

\begin{abstract}
Non-governmental Organisations are key development partners who receive funds and other support from various stakeholders for supporting human development. Receiving funds and other supports require a well-established accountability framework to which most NGOs do not adhere. The downward and upward accountability phenomena seem overly complicated for NGOs to strike a balance as they have diverse and antagonistic interests. Given that scenario, it was imperative to examine how the existing mechanisms, influence the accountability of NGOs with the bias of ANSAF, UCS and HAWA. The study used Dar es Salaam as the case study employing the case study research design with a sample size of 30 . Data were gathered through interviews and semi-structured questionnaires and analysed through content analysis for qualitative data. Quantitative data were analysed through simple descriptive statistics. This study aims to examine the mechanisms selected NGOs employ to in stil accountability in Tanzania. The study found that the selected NGOs apply various accountability mechanisms, while the most used one is performance assessment based on a short-term basis, followed by disclosure of funding sources. The study concludes that upward and downward accountabilities are overly complex phenomena in actual practice. Thus, NGOs needa proper dedicated balance between the two.
\end{abstract}

\section{Introduction}

In recent years, NGO accountability has emerged as a significant debate on strict state control to selfregulation (Jordan \& van Tuijl, 2012). In other words, NGOs' accountability has gained momentum in this contemporary world whereby there have been various debates regarding NGOs accountability across the world. This is because NGOs receive financial, technical and moral support from various stakeholders, but others feel that they do not achieve much of what has been promised and question accountability to prove their assertion (Ah Shin et al., 2018).

In the broadest sense, accountability is often used as a synonym for responsiveness, responsibility, and effectiveness. Within the context of political discourse and policy documents, accountability is often associated with transparency and trustworthiness (Spraul, 2017). In the literature, many authors view accountability as to how individuals and organisations report to a recognised authority (or authorities) and are held responsible for their actions (Werekoh, 2016). Therefore, accountability is also seen as answerability. Others focus more on a moral and ethical perspective of accountability (Mooketsane, 2018).

Concerns about accountability in NGOs have increased over the past two decades, due in part to a series of highly publicised scandals that have eroded public confidence in non-profit organisations, coupled with the rapid growth in NGOs around the world (Davis et al., 2020; Gibelman \& Gelman, 2001; Keating, Vincent Thrandardottir, 2018; Vandergeest \& Marschke, 2020). However, the growth of NGOs in various countries has been fueled by a belief among donors that NGOs are more cost-effective than governments in supplying 
essential social services (Dibie \& Okere, 2015; Hossain \& Paul, 2018). Although this seems correct, NGOs cannot render their activities without getting support from the government. Therefore, NGOs to prosperously perform their tasks need government support; likewise, the government needs NGOs as one of the imperative actors in the development process.

\section{Literature Review}

Accountability mechanism as a term has been described in detail in the work of Ebrahim (Ebrahim, 2003) and the book by Ebrahim and Weisband (2007), who refers to mechanisms for accountability as 'discrete devices or techniques used to achieve accountability.' The study further clarifies the five mechanisms of accountability applied in non-governmental organisations to include "reports and disclosure statements, performance assessments and evaluations, participation, self-regulation, and social audits". This study which focuses on non-governmental organisations revealed a disturbing challenge on accountability that NGOs typically focus on upward and external accountability due to the powers held by the government and donors whom they become accountable upwardly and externally. However, the downward and external accountability, which requires NGOs to be accountable to employees and the community where they serve, proves to be limitedly considered. Also, this study revealed that most NGOs conduct their accountability programmes through a short-term framework, making it impossible to hold them accountable on a long-term basis.

In another study by Goncharenko (2018) on the NGOs accountability of the online community, it was revealed that NGOs play a vital role in holding their members accountable for their actions. It was further noted that in the presence of improper accountability mechanisms such as inadequate reporting and weak systems to control performance, NGOs fail miserably to attain the accountability agenda.

The study by Baur and Schmitz (2012) on corporations and NGOs accountability provides another exciting observation on accountability mechanisms that corporations, through their corporate social responsibility programmes, should consider NGOs as partners in development instead of exerting more pressure on NGOs as well as eroding their independence which leads to ineffectiveness on the side of NGOs. The study emphasised more downward accountability among NGOs to regain their autonomy and reduce pressure from funders.

Tracing another accountability study conducted in Ethiopia also reveals the NGO accountability mechanisms, as explained by Hailu (2019)Click or tap here to enter text.. An ethnography of mechanisms employed by the government to hold NGOs in Ethiopia accountable: the case of child-focused social protection providers (Hailu, 2019). The study was an ethnography and applied interview and focus group approaches to collect data. This study noted that government initiatives through institutional frameworks enhance upward accountability mechanisms. However, there is a need to further downward accountability for NGOs in Ethiopia.

Van Zyl and Claeyé, 2019) provided an insightful study on NGOs' accountability mechanisms that intended to examine the trends and roles of downward and upward accountability, hence recommending which way to pursue. The study highlights the ongoing trend among NGOs to consider more upward accountability and ignore the downward accountability where the local NGOs become even more critical because the members of NGOs are the same community they serve. Thus, the study recommends further studies on the best ways to enhance downward accountability mechanisms for NGOs.

Apart from the above study by Van Zyl and Claeyé (2019), another study by Van Zyl et al. (2019) on accountability differences between local and non-local NGOs conducted in South Africa revealed the differences in accountability focus between these NGOs categories. In this study, it was noted that small and primarily local NGOs claim to align to downward accountability while non-local NGOs claim to align to upward accountability. As a result of accountability gaps between these NGOs categories, the study 
recommends learning from each other to complement their knowledge and practice on upward and downward accountability.

The issue of NGOs accountability mechanisms seems to be a global challenge as many NGOs are left in the closed box regarding the best ways to balance the upward and downward accountability mechanism, as revealed in the study by Islam (2019) conducted in Bangladesh. The study was qualitative that employed focus group and interview as data collection methods. The study found that NGOs are easily trapped to adhere to upward accountability to government and donors while putting less weight on downward accountability to communities.

The last study on accountability mechanisms for NGOs conducted in Uganda by Bukenya (2016) revealed the potential for communities such as people living with HIV-Aids to engage in social accountability only for NGOs to enhance them in that capacity which they lack. However, the study noted a lack of capacity among the community and NGOs based on government answerability through a political system and ignoring social accountability.

Organisations in Tanzania, including NGOs, are also subjected to accountability mechanisms. As noted through the literature, most organisations worldwide face the accountability challenges reflected in the upward and downward paradigm. Hence, as noted in the study by Goddard (2020), balancing accountability is challenging in Africa, including Tanzania.

\section{Methodology}

\subsection{Research Approach}

The study employed a mixed study approach with a case study design that allows in-depth study of a problem, enabling data analysis for a more profound understanding of the phenomenon and comparing cases (Creswell \& David Creswell, 2018). The study was conducted in Dar Es Salaam, Tanzania and included three organisations, namely Agricultural Non-State Actors (ANSAF), Upendo Community Survival (UCS), and Haki za Wanawake and Development (HAWA). Thus, the employees of these selected organisations were the population of the study. The study used 30 employees as a sample size, including 25 project officers and 5 senior officials, with a purposive sampling technique as a preferred non-probability sampling technique. During the study, the researcher collected both primary and secondary data. Primary data were gathered through semi-structured questionnaires, which enabled the collection of quantitative and qualitative data. Secondary data were collected through accountability and organisational reports. Data analysis was completed using content analysis for qualitative data, while quantitative data were analysed using simple descriptive analysis through percentage and frequency.

\section{Findings}

\subsection{Disclosure of Funding Sources to Stakeholders}

The study, through the responses from project officers, as seen in Table 1, found that $21(84 \%)$ respondents agreed that their NGOs do disclose funding sources to stakeholders such as community members as part of their accountability mechanisms. Other $2(8 \%)$ respondents in this study were neutral to the question on disclosure of funds, while the other $2(8 \%)$ disagreed that their organisations do disclose information on funding sources for their activities. Furthermore, respondents provided that the primary approach they use to disclose information to their stakeholders about their funding sources through a notice board and project reports publicly shared and can be accessed by anyone upon their interest.

The study also intended to explore more on the disclosure of funding sources from the senior officers' perspectives. The study, therefore, analysed the responses from senior officials who participated in a study through an in-depth interview. The study found that disclosure of funding sources is a widespread practice in many NGOs as it is required by both the government through the NGOs Act and most donors. Once they fund the project, they tend to be recognised by the official signpost, usually found outside the office and even 
in official documents' logo. Some officials said, In this era, there is no way you can hide the source of your funds as an NGO. This is because the law in the first place requires you to declare not only your funds but also your expenditures to the community.' The officials further clarified that 'the main methods which they declare their funding source to the community is through a public meeting where they organise for an entry or project introduction meeting, put their income and expenditure reports in their office notice boards and through project reports.'

Table 1: Disclosure of Funding Sources

\begin{tabular}{|c|c|c|c|}
\hline S/N & Response & Frequency & $\%$ \\
\hline 1 & Agree & 21 & 84 \\
\hline 2 & Neutral & 2 & 8 \\
\hline 3 & Disagree & 2 & 8 \\
\hline 4 & Total & 25 & 100 \\
\hline
\end{tabular}

Source: Field Survey (2020)

\subsection{Upward Accountability as the Most Demanding Accountability}

The study intended to determine whether upward accountability (reporting financial and activity details to the government and donors) is regarded as the most demanding accountability during project implementation. The study, through the responses of project officers, as seen in Table 2, noted that 17 (68\%) of the respondents agreed that upward accountability is the most demanding form of accountability in their practices. Additionally, 3 (12\%) of respondents were neutral about whether upward accountability was the most demanding form of accountability. Furthermore, the study noted that 5 (20\%) of respondents disagreed that upward accountability is the most demanding form of accountability. Specifically, respondents from the project officers' category provided further details of why they perceive this form of accountability to be the most demanding and time-consuming. Respondents provided that to attain accountability to government authorities requires much paperwork through reports and particular forms to fill. Also, it has financial implications for annual fees and other related documents and registration compliance issues. These processes cannot be completed in a short time.

On the other side, the study analysed collected data from senior officials of the selected NGOs under study. The respondents concurred with the findings from project officers that upward accountability is demanding and stressful to the selected NGOs. Some respondents argued that' The upward accountability is the form of accountability which runs in line with the whole project processes, it consumes the most time of project implementation as financial and project reports are highly needed'. Furthermore, the leaders of NGOs commented that' The reason most NGOs handle upward accountability with care is that it is dealing with those in power such as the government and donors of which they can revoke or terminate your existence instantly'.

Table 2: Upward Accountability as the Most Demanding Accountability

\begin{tabular}{|c|c|c|c|}
\hline S/N & Response & Frequency & $\%$ \\
\hline 1 & Agree & 17 & 68 \\
\hline 2 & Neutral & 3 & 12 \\
\hline 3 & Disagree & 5 & 20 \\
\hline 4 & Total & 25 & 100 \\
\hline
\end{tabular}

Source: Field Survey (2020)

\subsection{Downward Accountability as the Easiest Form of Accountability}

The researcher in this part intended to determine whether downward accountability is the easiest form of accountability mechanism employed by the selected NGOs. As noted in Table 3, through the project officers' category of respondents, the study found that 16 (64\%) respondents agreed that downward accountability (reporting financial and activities details to the community) is the easiest form of 
accountability. On top of that, $5(20 \%)$ respondents were neutral regarding the ease of downward accountability, while $4(16 \%)$ respondents disagreed that downward accountability is the easiest form of accountability for the selected NGOs during their day-to-day operations.

The study also explored the views of the senior officers of the selected NGOs through in-depth interviews. The study noted that while upward accountability was demanding and held with care, the downward accountability was relatively easy, flexible and not as bound as upward accountability. The respondents commented that' The downward accountability in most cases is conducted as a formality as many community members do not read or make follow-ups on financial and project reports posted on notice boards, websites and even hard copies found in the library'. That means many local people or community members are not interested in what NGOs are doing to hold those NGOs accountable.

Table 3: Downward Accountability as the Easiest Form of Accountability

\begin{tabular}{|c|c|c|c|}
\hline S/N & Response & Frequency & $\%$ \\
\hline 1 & Agree & 16 & 64 \\
\hline 2 & Neutral & 5 & 20 \\
\hline 3 & Disagree & 4 & 16 \\
\hline 4 & Total & 25 & 100 \\
\hline
\end{tabular}

\section{4. $\quad$ Assessment of Performance on Short Term Basis}

The accountability mechanisms for non-governmental organisations include assessing performance as one of the noted mechanisms applied by organisations through their day-to-day activities. On the same purpose to explore accountability mechanisms, the study intended to examine whether the selected NGOs assess their performance on a short-term basis (6 months to 3 years). The study explored the matter by asking project officers whether they conduct performance assessments on a short-term basis. As noted in Table 4 below, it was found that $23(92 \%)$ of the respondents agreed that they conduct a performance assessment of their organisations on a short-term basis covering six months to 3 years. Furthermore, the study findings indicated that one respondent (4\%) opted for neutrality on the issue and another one respondent (4\%) resorted to disagree that the selected NGOs conduct an assessment of their performance on a short-term basis.

Additionally, the study collected information based on qualitative data from senior officers of the selected NGOs. The study noted the same findings as the above collected from project officers, whereby the senior officers offered additional information that data the assessment they conduct are based on quarterly, semiannual and annual performance assessments. Also, at the end of the project, whether after one year, two or three years, they offer a complete performance report. The respondents highlighted that 'Assessment of performance is a requirement for most NGOs to keep on receiving fund, applying for a new fund, and submitting a report to the government for continuation of services.' The seniors clarified that most organisations assess their performance through a standardised tool known as the monitoring and evaluation (M\&E) framework. The seniors from ANSAF, UCS, and HAWA further mentioned another tool used to assess NGOs' performance, especially by donors, before extending their support to a specific project known as organisational capacity assessment (OCA). They stated that 'OCA is like entrance conditions that assess the organisation capacity to conduct a certain project as revealed in the earlier submitted funding proposal. After we get through the OCA stage, we can be sure that we are about to get funding support from donors.' 
Table 4: Assessment of Performance on Short-Term Basis

\begin{tabular}{|c|c|c|c|}
\hline $\mathrm{S} / \mathrm{N}$ & Response & Frequency & $\%$ \\
\hline 1 & Agree & 23 & 92 \\
\hline 2 & Neutral & 1 & 4 \\
\hline 3 & Disagree & 1 & 4 \\
\hline 4 & Total & 25 & 100 \\
\hline
\end{tabular}

Source: Field Survey (2020)

\subsection{Assessment of Performance on Long-term Basis}

Apart from the above-presented findings, which traced the use of performance assessment on a short-term basis, in this part, the researcher intended to determine whether NGOs assess their performance on a longterm basis, usually beyond five (5) years. The study revealed that most $11(44 \%)$ respondents disagreed that the selected NGOs conduct performance assessment on a long-term basis through the semi-structured questionnaire shared with project officers. Other $10(40 \%)$ respondents were neutral, while the minority respondents' category of $4(16 \%)$ respondents agreed that they performed the performance assessment on a long-term basis.

To complement the above findings, the study sought to inquire from senior officials through the interviews where it was similarly noted that performance assessment on a long-term basis is not common for most organisations, especially the small and middle ones. The interviewed seniors provided that 'Many projects we conduct are funded on a short-term basis, usually in six months, one year, two years, up to three years which makes it difficult for us to assess the performance of such projects on a longer-term basis as you can see there is no motivation for doing that.'

Table 5: Assessment of Performance on Long-term Basis

\begin{tabular}{|c|c|c|c|}
\hline $\mathrm{S} / \mathrm{N}$ & Response & Frequency & $\%$ \\
\hline 1 & Agree & 4 & 16 \\
\hline 2 & Neutral & 10 & 40 \\
\hline 3 & Disagree & 11 & 44 \\
\hline 4 & Total & 25 & 100 \\
\hline
\end{tabular}

Source: Field Survey (2020)

\subsection{Conduction of Internal Evaluation to Assess the Accountability Level to the Public}

Another aspect of the accountability mechanism is internal evaluation, whereas the study intended to explore whether NGOs conduct an internal evaluation to assess their accountability conduct to the public. Through the responses from project officers, the study revealed that $12(48 \%)$ respondents are the majority in this category, disagreed that the selected NGOs conduct an internal evaluation process to assess their accountability to the public. Other $3(12 \%)$ respondents were neutral on this matter, while $10(40 \%)$ respondents agreed that they conducted an internal evaluation for accountability purposes. The majority of respondents clarified that it is hard to conduct an internal evaluation as to the nature of NGOs' activities. A tight schedule characterises the whole period of the project activities, focusing on crucial activities; hence, extra activities such as self-evaluation are of less priority.

Additionally, the study examined the views of senior officers who asserted that the selected organisations' internal evaluation process is informal and only for internal use instead of public use. They further clarified that' Internal evaluation is the process many NGOs do even though they may not be aware of it. The internally scheduled and unscheduled feedback meetings to evaluate, assess and recommend the project activities are the same internal evaluation referred here, and the only challenge is that sometimes these 
meetings are very informal hence lacking records'.

Table 6: Conduction of Internal Evaluation to Assess the Accountability Level to the Public

\begin{tabular}{|c|c|c|c|}
\hline S/N & Response & Frequency & $\%$ \\
\hline 1 & Agree & 10 & 40 \\
\hline 2 & Neutral & 3 & 12 \\
\hline 3 & Disagree & 12 & 48 \\
\hline 4 & Total & 25 & 100 \\
\hline
\end{tabular}

Source: Field Survey (2020)

\subsection{Formal Assessment of NGOs' Performance by Communities}

Apart from conducting an internal assessment, the study sought to determine whether NGOs offer formal opportunities for communities where they operate to assess NGOs' performance. Through the responses from project officers, the study noted that the majority $11(44 \%)$ respondents disagreed that communities are offered a formal opportunity to assess the performance of NGOs. Another 8 (32\%) respondents were neutral regarding the extension of formal assessment opportunities to communities, while 6 (24\%) respondents agreed that communities are offered opportunities to assess NGOs' performance. The respondents further clarified that communities are not involved in formal assessment exercises, which a respective NGO prepares. In most cases, members of the communities are taken and prepared by the NGOs to give feedback to donors, of which the feedback is always positive because the NGOs' management tips them off.

The other response from senior officials reveals a limited formal opportunity for the community members to assess the performance of the NGOs. Most opportunities offered are for the selected vital persons to attend feedback meetings related to project activities. Some respondents asserted that' Formal opportunity for community members to provide their feedback regarding project activities is plenty. This is typically reflected through stakeholders' meetings, typically a requirement in most community projects. However, it is rare to find such a meeting which requires explicit community members to assess the NGOs performance.'

Table 7: Formal Assessment of NGOs' Performance by Communities

\begin{tabular}{|c|c|c|c|}
\hline S/N & Response & Frequency & $\%$ \\
\hline 1 & Agree & 6 & 24 \\
\hline 2 & Neutral & 8 & 32 \\
\hline 3 & Disagree & 11 & 44 \\
\hline 4 & Total & 25 & 100 \\
\hline
\end{tabular}

Source: Field Survey (2020)

\section{Discussion of Findings}

\subsection{Disclosure of Funding Sources to Stakeholders}

Through the responses from project officers, the study found that 21 (84\%) respondents, who are the majority, agreed that their NGOs do disclose funding sources to stakeholders such as community members as part of their accountability mechanisms. Furthermore, respondents provided the primary approach they used to disclose information to their stakeholders about their funding sources through notice boards and project reports publicly shared and accessed by anyone upon their interest.

The study also explored more on disclosure of funding sources from the senior officers' perspectives. The study found that disclosure of funding sources is standard in many NGOs as required by both the government through NGOs and most donors. Once they fund the project, donors are recognised by an official signpost usually located outside the office and even their logo in official documents. Sharma (2013) supports the above findings, who asserts that financial information disclosure is a crucial thing for 
organisations, and there are numerous theories such as agency theory, accounting theory, and a financial theory that support the matter. In another study by Thijssens et al. (2015), the literature suggests that as long as financial disclosure is essential for NGOs, primary and secondary stakeholders hold a crucial role in ensuring NGOs disclose their sources of funds and other financial information. Additionally, the study by Good et al. (2015) insists on the relevance of disclosing financial information for NGOs. The study showed that the disclosure of funding information could use an internet channel that people can easily access and similarly indicates the commitment of the respective NGOs.

Additionally, the stakeholder theory provides a basis for disclosing funds through a 'transparency' pillar. A study by Good et al. (2015) described the stakeholder theory concerning its contribution in disclosing information, and it stresses that stakeholders should know everything about an organisation.

The above findings and the associated literature imply that disclosing funding sources and related financial information is standard among NGOs. Furthermore, the practice is of great significance that involves both primary and secondary stakeholders. Apart from the traditional ways of using notice boards to disclose their funding information, NGOs should utilise the internet for the same purpose.

\subsection{Upward Accountability as the Most Demanding Accountability}

Through the responses of project officers, the study noted that $17(68 \%)$, who are the majority of all respondents, agreed that upward accountability is the most demanding form of accountability in their practices.

On the other side, the study analysed the collected data from senior officials of the selected NGOs under study. The respondents concurred with the findings from project officers that upward accountability is demanding and stressful to the selected NGOs.

The above findings are supported by Agyemang et al. (2017), who conducted a study on upward accountability where it was noted that NGOs do not have control over upward accountability, hence affecting their commitment toward adherence to accountability. Furthermore, upward accountability is burdensome in that it requires some severe form of compliance skills. In another study by Farrukh (2018) noted that upward accountability is a challenging form of accountability that requires critical attention to deal with. In this challenging context of upward accountability, NGOs should focus on a dialogue approach to manage its impact. In another study by Masdar (2015), the same existing challenges of upward accountability for NGOs still exist, and thus it is challenging to apply upward accountability as it is. Hence, NGOs tend to employ informal and formal upward accountability as the application of only one form leads to ineffectiveness.

The stakeholder theory highlights why upward accountability seems to be more demanding and pressing, as provided by Kim (2011) and that stakeholder theory emphasises those in direct relation to the organisation, including donors and government. Hence, stakeholders beyond the inner circle are not considered.

Therefore, concerning the specific findings of this study and the literature discussed above, it is noted that upward accountability is not an easy task among NGOs. This implies that NGOs should take extra effort and innovations to comply with this form of accountability as failure to apply extra effort and innovations, funding access, and support will be denied to them.

\subsection{Downward Accountability as the Easiest Form of Accountability}

Through the project officers' category of respondents, the study found that the majority, 16 (64\%) of the respondents, agreed that downward accountability (reporting financial and activities details to the community) is the easiest form of accountability.

The study also explored the views of the senior officers of the selected NGOs through in-depth interviews. The study noted that while upward accountability was demanding and held with care, the downward accountability was relatively easy, flexible and not as bound as upward accountability. 
The above findings are also in line with Bawole and Langnel (2016) study, who conducted a study on downward accountability among NGOs. The study found that downward accountability is such an easy form of accountability that sometimes NGOs do it just as a formality and that community involvement should logically be great but, in reality, is limited. In another study on accountability by Andrews (2014) reveals that NGOs do not take downward accountability in its heavyweight; instead, they take it as an easy form of accountability because due to the demanding upward accountability, they feel less responsible for downward accountability that caters for the concerns of community members. Additionally, the study of Jacobs and Wilford (2010) confirms the findings in this study that downward accountability has flexibility features that allow modifications on the side of implementers to suit their environment, contrary to upward accountability.

The study by Wellens and Jegers (2014) enlights a relevant connection between stakeholder theory and downward accountability. The study confirmed that downward accountability is crucial, and thus, perceptions of beneficiaries matter a lot, and without them, the stakeholder theory is incomplete.

The above findings imply that although downward accountability is stressed to be among the primary forms of accountability but in practice, it is less demanding; hence many NGOs do not take it seriously. Hence, members of the community are denied their right to hold NGOs accountable in their environment.

\subsection{Assessment of Performance on Short Term Basis}

The accountability mechanisms for non-governmental organisations include assessing performance as one of the noted mechanisms applied by organisations through their day-to-day activities. With the same purpose to explore accountability mechanisms, the study intended to examine whether the selected NGOs assess their performance on a short-term basis (6 months to 3 years). The study explored the matter by asking project officers where it was found that the majority, $23(92 \%)$ of the respondents, agreed that they conduct a performance assessment of their organisations on a short-term basis covering six months to 3 years.

Additionally, the study collected information based on qualitative data from senior officers of the selected NGOs. The study noted the same findings as the above collected from project officers, whereby the senior officers offered additional information that the assessment they conduct is based on quarterly, semi-annual and annual performance assessments. Also, at the end of the project, whether after one year, two or three years, they offer a complete performance report.

Concerning the field findings above, there is enough literature that provides evidence on NGOs' performance practices based on a short-term basis. The study by (N. Oppong, 2018) provides that NGOs conduct a short-term assessment using internal systems. However, the performance assessment, which focuses on the economy and efficiency of resources, is sometimes ineffective due to a lack of strategic focus. In another study by Abou Assi and Trent (2020) on the outset of NGOs practices, the focus on assessment activities is short-term instead of longer-term practices. Furthermore, the study by Roka (2012), which was conducted in Nepal, highlights the necessary practice of NGOs that a short-term-based community approach for assessment has been practical to some extent. To sum up more studies in this part, the study by Hielscher et al. (2016) reveals that performance assessment is a critical role that can save the organisation and set the basis for accountability even though done in the short-term run. However, if not done, it can put organisations in moral dilemmas for accountability.

The study by Bahadorestani et al. (2020), which provided a link to using a theoretical framework based on stakeholder theory, confirms the significant role of stakeholders in assessing the project performance. However, the performance assessment lacks strategic and sustainable focus means they are more concerned with the short-term as stakeholders are not fully engaged.

The above findings and literature imply that performance assessment on a short-term basis is common among NGOs, especially small and medium-sized ones. These NGOs get funding on a short-term basis only, 
such as six months to three years and rarely for the period above three years. Even though helpful to some extent, the short-term performance assessment denies organisations to measure the long-term impact (outcomes) of the project they perform.

\subsection{Assessment of Performance on Long-term Basis}

Through the semi-structured questionnaire shared by project officers, the study revealed that the majority of $11(44 \%)$ respondents disagreed that the selected NGOs conduct performance assessment on a long-term basis. To complement the above findings, the study sought to inquire from senior officials through the interviews where it was similarly noted that performance assessment on a long-term basis is not typical for most organisations, especially the small and middle ones.

As highlighted in the above findings by project officers and senior officers who asserted that most NGOs do not perform the long-term assessment as supported by studies such as the one conducted by Boomsma and O'Dwyer (2019) who provided that although the NGO focus on accountability has been improved, however many organisations lag on strategic focus. Similarly, the study by Reiser and Kelly (2011) reveals that NGOs' accountability has been regarded as a crucial part to foster global governance and strategic assessment that can enhance sustainability focus. However, the sustainability focus has been a significant challenge among many NGOs, hence the failure to realise the anticipated outcome. Apart from the above literature, Schmitz et al. (2012) support the argument that NGOs assessment among small NGOs is still a challenge as NGOs focus is determined by the financial performance and the assessment by other organisations, mainly donors. This practice eliminates the strategic and sustainable performance assessment, focusing on the longterm impact that stakeholders of the organisations desire.

A study by Hörisch et al. (2014) confirms that the application of stakeholder theory in strategic focus that includes long term goals and long-term assessment is challenging. This lack of sustainable management can affect organisations, and the above researchers highlight the causes of the pinpointed challenge that; it is challenging to manage the relationships among stakeholders. It is hard to fulfil stakeholders' interests, and lastly, it is not easy to enhance the capacity among stakeholders to achieve sustainable impact.

The above findings from the literature and study findings imply that performance assessment among most NGOs does not measure their project outcomes as they focus on issues such as financial performance and achievement of objectives that are short- term based. Thus, they fail in long-term accountability, which is an essential aspect of non-governmental organisations. This may be attributed to the fact that many existing NGOs are either small and others are mid-size whose projects are also short-term oriented.

\subsection{Conduction of Internal Evaluation to Assess the Accountability Level to the Public}

Another aspect of the accountability mechanism is internal evaluation, whereas the study intended to explore whether NGOs conduct an internal evaluation to assess their accountability behaviour to the public. Through the responses from project officers, the study revealed that $12(48 \%)$ respondents are the majority in this category, disagreed that the selected NGOs conduct an internal evaluation process to assess their accountability to the public.

Additionally, the study examined the views of senior officers who asserted that the selected organisations do the internal evaluation process but, in most cases, is informal and only for internal uses instead of public use. Conducting internal assessment for NGOs is among the essential mechanisms for ac- countability that NGOs can rely upon to determine their impact and execute some improvement programmes. However, as noted in the above findings, many NGOs do not conduct an internal evaluation process to determine their accountability levels to the communities they serve. This is also supported by scholars such as Lempert (2015), who provided that NGOs established indicators to conduct their internal evaluation from which they can know their accountability level. Due to the multiplicity of indicators, small NGOs found themselves not adhering to the indicators established, hence missing the internal evaluation for accountability. 
In another way, Stolfova and Fajfrlikova (2019) argue that internal evaluation is about feedback that can enable NGOs to assess their accountability to the people they serve. This also facilitates their personal growth and professional practices for those NGOs which conduct such a process.

In the study conducted by 'Leary (2017), it was confirmed that internal evaluation is a self-determination process that instils accountability to service providers in an NGO. This accountability assures the project beneficiaries in the community that the resources received by NGOs on their behalf are appropriately managed. Hence, the process helps enhance the accountability relationship between communities and NGOs. Oppong et al. (2016), in their study, reveal that the internal evaluation practices enhance internal controls, which then get reflected into accountability practices. These practices, on top of enhancing accountability but also help improve the performance of NGOs. Despite the significance of internal evaluation systems, many organisations, especially small NGOs, do not have these systems; hence, they lack accountability.

Additionally, the stakeholder theory emphasises the role of internal and external stakeholders, including the evaluation role, because stakeholders need to experience the total value of the projects or organisational activities (Rafindadi \& Olanrewaju, 2019). Furthermore, the theory provides that the internal process can help evaluate accountability, as noted in the study by Farneti et al. (2019) that an integrated report within the internal evaluation process confirms the usefulness of internal stakeholders in evaluation processes.

According to the above discussion, it is evident that internal evaluation is a critical accountability practice that has benefits to organisations practising it. However, organisations, especially small ones, found it challenging to adhere to it. This implies that accountability practices through internal evaluation are limited as NGOs do not perform self-determination on their accountability practices.

\subsection{Formal Assessment of NGOs' Performance by Communities}

Through the responses from project officers, the study noted that the majority 11 (44\%) respondents disagreed that communities are offered a formal opportunity to assess the performance of NGOs.

The other response from senior officials reveals a limited formal opportunity for the community members to assess the performance of the NGOs. Most opportunities offered are for the selected vital persons to attend feedback meetings related to project activities.

In the work of Ranängen (2017) and Yuesti et al. (2016), the stakeholder theory seems to elaborate on the role of the external stakeholders, which may involve community members, government and others. The theory confirms that the involvement of external members in the evaluation of organisations' impact is what makes stakeholder theory meaningful.

The above findings revealed by project officers and senior officers are also backed up by the literature, which confirms that communities are not given formal opportunity to assess the performance of NGOs serving their communities. A study by Kinyua (2017) revealed that the poor community being on the recipient side of funding from donors could not assess the performance of their donors as to whether they are properly accountable for the resources that they receive on behalf of the poor community. Another study conducted in Vanuatu by Strychar and Day (2019) confirms that even though the formal opportunity for community assessment is not guaranteed but community members always have their concerns. This is justified by the concern of Vanuatu people who felt that community assessment is essential as they had issues with housing delivery services offered by NGOs. Awio et al. (2011) assert that the community-based assessment, also regarded as downward accountability, can complement formal upward accountability for the NGO by enriching them with potential feedback regarding what they offer to the people hence an opportunity for service delivery improvement as well. A study by Basel et al. (2020) re-affirms that if the community assessment is determined to be initiated and implemented by NGOs, it has to be participatory that deeply consider the views, concern and integrate inputs of communities.

The above findings of the study complemented by the discussed literature reveal that community assessment 
is a basic form of enhancing NGOs' accountability. However, it is alarming that most NGOs do not conduct a formal assessment by involving communities unless under the pressure of their donors, which signifies the process is poorly conducted.

Therefore, the findings and literature imply low accountability, compliance and a lack of readiness for NGOs to be assessed by community members formally. In such a context, NGOs may be hiding some issues to communities and attracting vices such as donors' fund embezzlement.

\section{Conclusion}

The study concludes that the issue of mechanisms for accountability among NGOs is a complex phenomenon that some organisations find themselves quickly relying on upward accountability and fail to achieve downward accountability. Furthermore, NGOs tend to assess performance on a short basis and leave behind long-term performance assessment.

\section{Recommendation}

First, NGOs are advised to ensure that their performance assessment also covers a long- term period of at least five years to capture their long-term impact or outcomes on their project for easy determining of their effectiveness in serving communities.

Secondly, NGOs are advised to improve their practices with downward accountability, including allowing the communities where they operate to assess their practices and thus rate them accordingly. This is among the ignored practices for accountability; therefore, practising this is credible to the organisations.

Thirdly, NGOs should ensure their internal evaluation systems work and give them consistent feedback on their accountability practices, including feedback from employees. This is because many NGOs, especially the small and middle ones, ignore the formal internal evaluation practices hence score low in internal accountability practices.

\section{Reference}

[1] Abou Assi, K., \& Trent, D. (2020). NGO Accountability from an NGO Perspective: Their Perceptions, Strategies, and Practices. SSRN Electronic Journal. https://doi.org/10.2139/ssrn.3630087

[2] Agyemang, G., O'Dwyer, B., Unerman, J., \& Awumbila, M. (2017). Seeking "conversations for accountability": Mediating the impact of non-governmental organisation (NGO) upward accountability processes. Accounting, Auditing and Accountability Journal, 30(5). https://doi.org/10.1108/AAAJ-02-2015-1969

[3] Ah Shin, Y., Yeo, J., \& Jung, K. (2018). The effectiveness of international non-governmental organisations' response operations during public health emergency: Lessons learned from the 2014 Ebola outbreak in sierra leone. International Journal of Environmental Research and Public Health, 15(4). https://doi.org/10.3390/ijerph15040650

[4] Andrews, A. (2014). Downward Accountability in Unequal Alliances: Explaining NGO Responses to Zapatista Demands. World Development, 54. https://doi.org/10.1016/j.worlddev.2013.07.009

[5] Awio, G., Northcott, D., \& Lawrence, S. (2011). Social capital and accountability in grass-roots NGOs: The case of the Ugandan community-led HIV/AIDS initiative. Accounting, Auditing and Accountability Journal, 24(1). https://doi.org/10.1108/09513571111098063

[6] Bahadorestani, A., Naderpajouh, N., \& Sadiq, R. (2020). Planning for sustainable stakeholder engagement based on the assessment of conflicting interests in projects. Journal of Cleaner Production, 242. https://doi.org/10.1016/j.jclepro.2019.118402

[7] Basel, B., Goby, G., \& Johnson, J. (2020). Community-based adaptation to climate change in villages of Western Province, Solomon Islands. Marine Pollution Bulletin, 156. https://doi.org/10.1016/j.marpolbul.2020.111266

[8] Baur, D., \& Schmitz, H. P. (2012). Corporations and NGOs: When Accountability Leads to Cooptation. Journal of Business Ethics, 106(1). https://doi.org/10.1007/s10551-011-1057-9 
[9] Bawole, J. N., \& Langnel, Z. (2016). Downward accountability of NGOs in community project planning in Ghana. Development in Practice, 26(7). https://doi.org/10.1080/09614524.2016.1210094

[10] Boomsma, R., \& O'Dwyer, B. (2019). Constituting the governable NGO: The correlation between conduct and counter-conduct in the evolution of funder-NGO accountability relations. Accounting, Organisations and Society, 72. https://doi.org/10.1016/j.aos.2018.05.012

[11] Bukenya, B. (2016). From Social Accountability to a New Social Contract? The Role of NGOs in Protecting and Empowering PLHIV in Uganda. Journal of Development Studies, 52(8). https://doi.org/10.1080/00220388.2015.1134775

[12] Creswell, J. W., \& David Creswell, J. (2018). Research Design: Qualitative, Quantitative, and Mixed Methods Approaches (5th ed.). SAGE Publications.

[13] Davis, J. M., Henson, S., \& Swiss, L. (2020). In INGOs we trust? How individual determinants and the framing of INGOs influences public trust. Development in Practice, 30(6). https://doi.org/10.1080/09614524.2020.1801593

[14] Dibie, R., \& Okere, J. S. (2015). Government and NGOs Performance with Respect to Women Empowerment in Nigeria. Africa's Public Service Delivery and Performance Review, 3(1). https://doi.org/10.4102/apsdpr.v3i1.77

[15] Ebrahim, A. (2003). Accountability in practice: Mechanisms for NGOs. World Development, 31(5). https://doi.org/10.1016/S0305-750X(03)00014-7

[16] Ebrahim, A., \& Weisband, E. (2007). Global accountabilities: Participation, pluralism, and public ethics. In Global Accountabilities: Participation, Pluralism, and Public Ethics. https://doi.org/10.1017/CBO9780511490903

[17] Farneti, F., Casonato, F., Montecalvo, M., \& de Villiers, C. (2019). The influence of integrated reporting and stakeholder information needs on the disclosure of social information in a state-owned enterprise. Meditari Accountancy Research, 27(4). https://doi.org/10.1108/MEDAR-01-2019-0436

[18] Farrukh, A. (2018). Seeking 'Conversations for Accountability': Mediating the Impact of Nongovernmental Organisation (NGO) Upward Accountability Processes. In Social and Environmental Accountability Journal (Vol. $38, \quad$ Issue 2 2). https://doi.org/10.1080/0969160X.2018.1490080

[19] Gibelman, M., \& Gelman, S. R. (2001). Very public scandals: Non-governmental organisations in trouble. Voluntas, 12(1). https://doi.org/10.1023/A:1011242911726

[20] Goddard, A. (2020). Accountability and accounting in the NGO field comprising the UK and Africa - A Bordieusian analysis. Critical Perspectives on Accounting. https://doi.org/10.1016/j.cpa.2020.102200

[21] Goncharenko, G. (2018). The accountability of advocacy NGOs: Insights from the online community of practice. Accounting Forum. https://doi.org/10.1016/j.accfor.2018.12.002

[22] Good, K. J., Borba, J. A., \& Maragno, L. M. D. (2015). Supporting Stakeholder Relationship Management via Disclosure on Resource Origins: Evidence from the World's Top NGOs. Sociedade, Contabilidade e Gestão, 10(2). https://doi.org/10.21446/scg_ufrj.v10i2.13355

[23] Hailu, D. (2019). An ethnography of mechanisms employed by the government to hold NGOs in Ethiopia accountable: the case of child focused social protection providers. Arts \& Humanities Open Access Journal, 3(1). https://doi.org/10.15406/ahoaj.2019.03.00098

[24] Hielscher, S., Winkin, J., Crack, A., \& Pies, I. (2016). Saving the Moral Capital of NGOs: Distinguishing Social Dilemmas in NGO Accountability. Academy of Management Proceedings, 2016(1). https://doi.org/10.5465/ambpp.2016.13894abstract

[25] Hörisch, J., Freeman, R. E., \& Schaltegger, S. (2014). Applying Stakeholder Theory in Sustainability Management. Organization \& Environment, 27(4). https://doi.org/10.1177/1086026614535786

[26] Hossain, M. N., \& Paul, S. K. (2018). Vulnerability Factors and Effectiveness of Disaster Mitigation Measures in the Bangladesh Coast. Earth Systems and Environment, 2(1). https://doi.org/10.1007/s41748-018-0034-1

[27] Islam, M. S. (2019). Developing accountability mechanisms in NGOs in providing health services. International Journal of Healthcare Management. https://doi.org/10.1080/20479700.2019.1692993

[28] Jacobs, A., \& Wilford, R. (2010). Listen first: A pilot system for managing downward accountability in NGOs. Development in Practice, 20(7). https://doi.org/10.1080/09614524.2010.508113

[29] Jordan, L., \& van Tuijl, P. (2012). NGO accountability: Politics, principles and innovations. In $N G O$ 
Accountability Politics, Principles and Innovations. https://doi.org/10.4324/9781849772099

[30] Keating, Vincent Thrandardottir, E. (2018). Building Trust in NGOs. E-International Relations.

[31] Kinyua, K. (2017). The Poor Communities Interactions with Global Interventions: Examining NGOization in Kenyan Society. The Global Studies Journal, 10(3). https://doi.org/10.18848/18354432/cgp/v10i03/39-52

[32] Lempert, D. (2015). A quick indicator of effectiveness of "capacity building" initiatives of NGOs and international organisations. European Journal of Government and Economics, 4(2). https://doi.org/10.17979/ejge.2015.4.2.4312

[33] Masdar, N. M. Hj. (2015). The Practices of Upward Accountability in the Malaysian NGO. Procedia Economics and Finance, 31. https://doi.org/10.1016/s2212-5671(15)01142-9

[34] Mooketsane, K. (2018). Strengthening Non-governmental Organisations Accountability through Beneficiaries' Participation: The Case of NGOs in Botswana.

[35] O'Leary, S. (2017). Grassroots accountability promises in rights-based approaches to development: The role of transformative monitoring and evaluation in NGOs. Accounting, Organisations and Society, 63. https://doi.org/10.1016/j.aos.2016.06.002

[36] Oppong, M., Owiredu, A., Abedana, V. N., \& Asante, E. (2016). The Impact of Internal Control on The Performance of Faith-Based NGOs in Accra. Research Journal of Finance and Accounting, $7(12)$.

[37] Oppong, N. (2018). Negotiating transparency: NGOs and contentious politics of the Extractive Industries Transparency Initiative in Ghana. Contemporary Social Science, 13(1). https://doi.org/10.1080/21582041.2017.1394483

[38] Rafindadi, A. A., \& Olanrewaju, Z. A. (2019). THE IMPACT OF INTERNAL CONTROL SYSTEM ON THE FINANCIAL ACCOUNTABILITY OF NON-GOVERNMENTAL ORGANISATIONS IN NIGERIA: EVIDENCE FROM THE STRUCTURAL EQUATION MODELLING. International Review of Management and Marketing, 9(3). https://doi.org/10.32479/irmm.7909

[39] Ranängen, H. (2017). Stakeholder management theory meets CSR practice in Swedish mining. Mineral Economics, 30(1). https://doi.org/10.1007/s13563-016-0098-z

[40] Reiser, D. B., \& Kelly, C. R. (2011). Linking NGO accountability and the Legitimacy of Global Governance. Brooklyn Journal of International Law, 36(3).

[41] Roka, K. B. (2012). Are NGOs making a difference? A community approach to measuring nongovernment organisations (NGOs) effectiveness in Nepal. In ProQuest Dissertations and Theses.

[42] Schmitz, H. P., Raggo, P., \& Bruno-van Vijfeijken, T. (2012). Accountability of Transnational NGOs: Aspirations vs Practice. Non-profit and Voluntary Sector Quarterly, 41(6). https://doi.org/10.1177/0899764011431165

[43] Sharma, N. (2013). Theoretical Framework for Corporate Disclosure Research. Asian Journal of Finance \& Accounting, 5(1). https://doi.org/10.5296/ajfa.v5i1.3210

[44] Spraul, K. (2017). Measuring Accountability in Non-profit Organisations: The Impact of Non-profit Governance on Accountability.

[45] Stolfova, A., \& Fajfrlikova, P. (2019). Development of employees' evaluation and motivation systems in Czech NGO. International Journal of Public Sector Performance Management, 5(1). https://doi.org/10.1504/IJPSPM.2019.096682

[46] Strychar, L., \& Day, J. (2019). Community assessment of NGO housing delivery: lessons from Port Vila, Vanuatu. Development in Practice, 29(4). https://doi.org/10.1080/09614524.2019.1575336

[47] Thijssens, T., Bollen, L., \& Hassink, H. (2015). Secondary Stakeholder Influence on CSR Disclosure: An Application of Stakeholder Salience Theory. Journal of Business Ethics, 132(4). https://doi.org/10.1007/s10551-015-2623-3

[48] van Zyl, H., \& Claeyé, F. (2019). Up and Down, and Inside Out: Where do We Stand on NGO Accountability? European Journal of Development Research, 31(3). https://doi.org/10.1057/s41287018-0170-3

[49] van Zyl, W. H., Claeyé, F., \& Flambard, V. (2019). Money, people or mission? Accountability in local and non-local NGOs. Third World Quarterly, 40(1). https://doi.org/10.1080/01436597.2018.1535893

[50] Vandergeest, P., \& Marschke, M. (2020). Modern Slavery and Freedom: Exploring Contradictions 
through Labour Scandals in the Thai Fisheries. Antipode, 52(1). https://doi.org/10.1111/anti.12575

[51] Wellens, L., \& Jegers, M. (2014). Beneficiary participation as an instrument of downward accountability: A multiple case study. European Management Journal, 32(6). https://doi.org/10.1016/j.emj.2014.03.004

[52] Werekoh, K. (2016). Accountability Systems of Non-governmental Organisations (NGOs): Case Study from Ghana.

[53] Yuesti, A., Novitasari, L. G., \& Rustiarini, N. W. (2016). Accountability of Non-Government Organization from the Perspective of Stakeholder Theory. International Journal of Accounting and Taxation, 4(2). https://doi.org/10.15640/ijat.v4n2a7

[54] 손혁상, \& SOWI KIM. (2011). Government-NGO Partnerships for International Development Cooperation: A Case Study of South Korea. Asian International Studies Review, 12(2). https://doi.org/10.16934/isr.12.2.201112.65 